\title{
The dynamics of D-dimer level fluctuation in patients after the cemented and cementless total hip and total knee replacement
}

Piotr Bytniewski ${ }^{1,2}$, Waldemar Machała ${ }^{3}$, Leszek Romanowski ${ }^{4}$, Wiesław Wiśniewski ${ }^{5}$ and Klaudiusz Kosowski ${ }^{6^{*}}$

\begin{abstract}
Introduction: The number of total hip and total knee replacement procedures performed worldwide has tended to surge in recent years, due to the combination of such factors as the increased life expectancy, improved quality of life, advances in medical technology as well as pre-operative and post-operative patient management. Numerous studies confirm that patients undergoing major orthopaedics procedures involving lower extremities, for instance total hip and total knee replacement, constitute the highest risk group for the development of post-operative venous thromboembolism (VTE), primarily manifested as deep vein thrombosis (DVT).
\end{abstract}

Purpose: The purpose of the research was to assess the dynamics of D-dimer level fluctuation during the post-operative period in patients after the cemented or cementless total hip replacement (THR) or total knee replacement (TKR), in order to prove or reject the thesis that the cemented and cementless THR or TKR affects the post-operative D-dimer levels.

Material and methods: The study group consisted of 47 patients aged 29-82 years. Of them, 23 had the cementless THR, 12 subjects had the cemented THR and another 12 patients had the TKR. All of the patients performed to measure the concentration of D-dimers in the peri-operative period at predetermined time points. For the peri-operative period was adopted from time 1 day before surgery to 10-day hospitalization. The subarachnoid block (SAB) was performed in all patients.

Results: The distribution of D-dimer values throughout the entire post-operative period (up to 10th post-operative day) followed the sinusoid pattern with two peaks in all patients. It was not specific in any group.

\section{Conclusions:}

1. The D-dimer level almost doubles during the post-operative period in patients after THR or TKR.

2. Higher level of D-dimers in post-operative period in the research group of patients does not relate to higher risk of thromboembolic disease.

Keywords: D-dimers, Total hip replacement, Total knee replacement

\section{Introduction}

D-dimers are fibrin degradation products formed as a result of fibrin clot dissolution by plasmin. They participate in the entire homeostasis mechanism including coagulation and fibrinolysis processes. Under physiological conditions, both processes should take place simultaneously, maintaining some balance.

\footnotetext{
* Correspondence: biuro@ortokos.pl

${ }^{6}$ Health Maintenance Organization in Turek, Turek, Poland Full list of author information is available at the end of the article
}

As long as the processes are normal and balanced, the body is protected against bleeding as well as against thrombus formation. When bleeding occurs, the appropriate mechanisms are activated leading to thrombus formation out of fibrin, which stops the bleeding. After the thrombus is dissolved by plasmin, the fibrin degradation products such as D-dimers are released. Their elevated plasma concentration indicates that the coagulation and fibrinolysis mechanisms were triggered. D-dimer level measurement is not included in the routine pre-operative
C Biomed Central 
laboratory panel. This test is typically done in patients with suspected venous thromboembolism (VTE), manifested as deep vein thrombosis (DVT) or pulmonary embolism (PE) [1]. But it may also be used as a part of diagnosis or monitoring of patients with disseminated intravascular coagulation (DIC) [2]. The term venous thromboembolism encompasses two elements: deep vein thrombosis and pulmonary embolism. It implies that while deep vein thrombosis is the primary manifestation of the disease, pulmonary embolism may follow as the sequelae.

Numerous studies confirmed that patients undergoing major orthopaedic procedures involving lower extremities, for instance total hip and total knee replacement, constitute the highest risk group for the development of post-operative venous thromboembolism, primarily manifested as the deep vein thrombosis [3-5]. The number of total hip and total knee replacement procedures performed worldwide has tended to surge in recent years, due to the combination of such factors as the increased life expectancy, improved quality of life, advances in medical technology as well as pre-operative and post-operative patient management. Although D-dimers are specific as fibrin degradation products, fibrin itself is not specific for venous thromboembolism only. The increased fibrin production, which is manifested by the elevated D-dimer concentration, can also be observed in other clinical conditions, such as cancer, infection, inflammation, surgery, injuries, haemorrhages, extensive burns, cerebral stroke, aortic aneurysm rupture, ischemic heart disease, myocardial infarction (MI), rheumatoid arthritis (RA), pregnancy and postpartum period as well as in elderly patients, patients with haematomas, extensive bruises and many others $[3,6,7]$.

The prospective studies show that the negative result of D-dimer assay, that is the value below the cutoff point (usually $500 \mathrm{ng} / \mathrm{ml}$ ), makes it possible to exclude the disease and to refrain safely from anticoagulation therapy in patients with moderate or low clinical potential for the venous thromboembolism, assessed using Wells prediction rules [8-11]. On the other hand, the elevated D-dimer level does not have a confirmatory value for venous thromboembolism due to low specificity of the assay. Therefore, the assay should not be used in order to diagnose DVT or PE, as not every patient with the elevated D-dimer level has an acute episode of VTE.

\section{Purpose}

The purpose of the research was to assess the dynamics of $\mathrm{D}$-dimer level fluctuation during the post-operative period in patients after the cemented or cementless total hip replacement (THR) or total knee replacement (TKR), in order to prove or reject the thesis that the cemented and cementless total hip or total knee replacement affects the post-operative $\mathrm{D}$-dimer levels.

\section{Material and methods}

Fifty patients (35 women and 15 men) aged $29-82$ years were enrolled in the study. All subjects gave their informed consent to participate in the study (informed consent form, patient information form). Twenty-three of them had the cementless THR, 15 subjects had the cemented THR and another 12 patients had the TKR. All procedures were performed in the Department of Orthopedics and Traumatology, Health Maintenance Organization in Turek. Three patients after the cemented THR were eventually excluded from the analysis, due to the impossibility to perform the D-dimer measurements at all required time points as a result of technical difficulties. Therefore, the final study sample consisted of 47 subjects (32 women and 15 men). The study protocol was approved by the Institutional Review Board at the Karol Marcinkowski Medical University of Poznań, by the virtue of Resolution no. 739/11.

Inclusion criteria:

- Degenerative hip or knee lesions, making the patient eligible for surgery

- Category I-III at the assessment of physical status classified according to the system developed by the American Society of Anaesthesiology (ASA)

- Health insurance holders (National Health Fund)

Exclusion criteria:

- Current diagnosis or a history of VTE

- Joint injury (involving the joint scheduled for surgery), within the last few days

- Infection

- Cancer

- Pregnancy

- Use of oral anticoagulants

- ASA category $>$ III

- Age $<18$ years

- Legal incapacity

Detailed medical history was obtained, and physical examination was performed in each patient prior to the scheduled surgery. The anamnesis involved the history of chronic diseases and surgery, all chronic comorbidities and their treatment as well as currently used VTE prevention. The respiratory and cardiovascular function was assessed during the physical examination. At the same time, the lower extremities were evaluated for varicose veins, and the type of total hip/knee implant was determined. Prior to the surgery, the following assays were routinely performed. None of the enrolled patients was diagnosed with venous thromboembolism based on clinical assessment and venous ultrasound scan. The perioperative period was referred to as the period from 
the 1st day preceding the surgery until the 10th day postoperatively, although this definition is broader than the ones commonly accepted in anaesthesiology.

In the whole peri-operative period, the $\mathrm{D}$-dimer level in blood plasma was assessed by immunoenzymatic automated quantity test VIDAS D-Dimer Exclusion carried out in the immunoanalyzer VIDAS and based on marking fibrin degradation products (FbDP) in human blood plasma (with sodium citrate) with the use of enzymelinked fluorescent assay (ELFA) technique. According to the data provided by the manufacturer (Bio-Merieux, Lyon, France), measuring range VIDAS D-Dimer Exclusion area from $45 \mathrm{ng} / \mathrm{ml}$ to $10,000 \mathrm{ng} / \mathrm{ml}$ cutoff point of $500 \mathrm{ng} / \mathrm{ml}$, the sensitivity of about $100 \%$, a negative predictive value (NPV) of about $100 \%$ and a specificity of about $40 \%$ [12].

The following time points have been assumed for the assays:

I. On the day preceding surgery-the pre-operative assay \# "0"

II. $12 \mathrm{~h}$ post-operatively-assay \# " 1 "

III. On the 1st post-operative day-assay \# "2"

IV. On the 2nd post-operative day-assay \# " 3 "

$\mathrm{V}$. On each consecutive day, until the 10th postoperative day-final assay \# "11"

All enrolled patients received VTE prevention, which involved administration of low molecular weight heparin at doses recommended by the Polish Society of Orthopaedics and Traumatology [13]. The preventive heparin use was prolonged up to 6 weeks post-operatively. The premedication administered approx. 40-50 min prior to the scheduled surgery involved Midazolam p.o. or i.m. at the dose of $0.07-0.1 \mathrm{mg} / \mathrm{kg}$. Moreover, each patient received $1.0 \mathrm{~g}$ of Metamizole sodium dissolved in $500 \mathrm{ml}$ of saline as an intravenous (i.v.) infusion. The subarachnoid block (SAB) was done in all patients using a single puncture technique with the patient sitting.

All patients were administered 1,000 mg of Tranexamic acid i.v. and infusion fluids at the dose of $20 \mathrm{ml} / \mathrm{kg}$ (i.e. approx. 1,500-2,000 ml) during the surgery. The administered infusion fluids comprised specifically of: $10 \%$ hydroxyethyl starch (HES) 200/0.5, $500 \mathrm{ml}$; the multielectrolyte solution, $500 \mathrm{ml} ; 0.9 \%$ sodium chloride (saline), $500 \mathrm{ml}$ plus potentially another $500 \mathrm{ml}$ bag. Moreover, if necessary, packed red blood cells, hydrocortisone (for cemented implants), sedatives (Midazolam) or other drugs were administered i.v. based on the physician's judgement. Atropine sulphate was also administered in cases of heart rate drop by $25 \%$ as compared to baseline value. Similarly, ephedrine hydrochloride was administered in cases of mean blood pressure drop by $25 \%$ as compared to the baseline value determined during the first
Table 1 Characteristics of the population of patients in terms of gender, age and including factors BMI and international ASA scale

\begin{tabular}{|c|c|c|c|}
\hline & \multicolumn{3}{|c|}{ Characteristics of the population of patients } \\
\hline \multicolumn{4}{|c|}{ All patients in study (47) } \\
\hline \multirow[t]{2}{*}{ Sex (\%) } & Female & Male & \\
\hline & 68.085 & 31.914 & \\
\hline \multirow[t]{5}{*}{ Subjects } & 32 & 15 & \\
\hline & ASA I & ASA $\|$ & ASA III \\
\hline & 12.766 & 31.915 & 55.319 \\
\hline & 6 & 15 & 26 \\
\hline & Min & Max & Mean value \\
\hline Age in years & 29 & 82 & 66.1 \\
\hline $\mathrm{BMI}(\mathrm{kg} / \mathrm{m} 2)$ & 21.273 & 41.207 & 29.557 \\
\hline \multicolumn{4}{|c|}{ Cementless total hip replacement (23) } \\
\hline \multirow[t]{2}{*}{ Sex (\%) } & Female & Male & \\
\hline & 60.87 & 39.13 & \\
\hline Subjects & 14 & 9 & \\
\hline \multirow[t]{2}{*}{ ASA (\%) } & ASA I & ASA \| & ASA III \\
\hline & 26.087 & 30.435 & 43.478 \\
\hline \multirow[t]{2}{*}{ Subjects } & 6 & 7 & 10 \\
\hline & Min & Max & Mean value \\
\hline Age in years & 29 & 75 & 58.696 \\
\hline $\mathrm{BMI}(\mathrm{kg} / \mathrm{m} 2)$ & 21.273 & 38.587 & 28.953 \\
\hline \multicolumn{4}{|c|}{ Total knee replacement (12) } \\
\hline & Female & Male & \\
\hline & 66.667 & 33.333 & \\
\hline Subjects & 8 & 4 & \\
\hline \multirow[t]{2}{*}{ ASA (\%) } & ASA I & ASA \| & ASA III \\
\hline & 0 & 50 & 50 \\
\hline \multirow[t]{2}{*}{ Subjects } & 0 & 6 & 6 \\
\hline & Min & Max & Mean value \\
\hline Age in years & 56 & 79 & 66.917 \\
\hline BMI (kg/m2) & 27.349 & 35.467 & 30.967 \\
\hline \multicolumn{4}{|c|}{ Cemented total hip replacement (12) } \\
\hline \multirow[t]{2}{*}{ Sex (\%) } & Female & Male & \\
\hline & 83.333 & 16.667 & \\
\hline \multirow[t]{5}{*}{ Subjects } & 10 & 2 & \\
\hline & ASA I & ASA $\|$ & ASA III \\
\hline & 0 & 16.667 & 83.333 \\
\hline & 0 & 2 & 10 \\
\hline & Min & Max & Mean value \\
\hline Age in years & 58 & 82 & 72.667 \\
\hline BMI (kg/m2) & 25.368 & 41.207 & 29.307 \\
\hline
\end{tabular}


measurement. During the anaesthesia, the measures were taken to prevent the blood pressure drop by $35 \%$ as compared to the baseline value.

\section{Statistical analysis}

As most of the studied variables did not follow normal distribution, the following non-parametric tests were used for the analysis:

- In order to verify the differences between the D-dimer levels at various time points within the same patient group, the Wilcoxon signed rank test was used.

- In order to verify the differences in percentage changes in D-dimer levels between the patient groups, the Mann-Whitney $U$-test was used.

- In order to assess the correlation between the baseline D-dimer level and the patient age, the Spearman's rank correlation coefficient was calculated.

The $p$ level of $<.05$ was assumed for all comparisons.

\section{Results}

Characteristics for all sampled groups of patients: cementless total hip replacement (cementless THR), TKR, cemented total hip replacement (cemented THR) in terms of gender, age, BMI, past history expressed and evaluated by the international ASA scale are presented in Table 1.

The pre-operative $\mathrm{D}$-dimer levels are presented in Table 2. The baseline D-dimer level exceeded the reference value of $500 \mathrm{ng} / \mathrm{mL}$ in 37 out of 47 subjects. In most cases, this excess was attributed to patient age and their comorbidities. The D-dimer levels in all subjects, measured $12 \mathrm{~h}$ post-operatively are presented in Table 2 .

The elevated D-dimer level at $12 \mathrm{~h}$ post-operatively was shown in 46 out of 47 subjects. It was the highest increase in D-dimer level observed throughout the entire follow-up period, which reached the peak of 10,000 ng/mL in almost half of the study group. Moreover, a statistically significant difference was found between the mean D-dimer levels at $12 \mathrm{~h}$ post-operatively and the baseline values across all study groups (cementless THR, $p<0.001$; total knee replacement, $p=0.002$; cemented THR, $p=0.006$ ). The $\mathrm{D}$-dimer levels in all subjects, measured on the1st post-operative day are presented in Table 2.

The D-dimer level decreased in all subjects on the 1st post-operative day compared to the level measured at $12 \mathrm{~h}$ post-operatively. However, the obtained values still exceeded the baseline levels. A statistically significant difference between the mean D-dimer level on the 1 st post-operative day, compared to the measurement $12 \mathrm{~h}$ post-operatively was shown in all groups (cementless THR, $p<0.001$; TKR, $p=0.003$; cemented THR, $p=0.008$ ). Similarly, a statistically significant difference between the D-dimer level on the 1st post-operative day and its baseline values was found across all groups (cementless THR, $p<0.001$; TKR, $p=0.002$; cemented THR, $p=0.034$ ). The lowest D-dimer levels on the 2 nd-3rd post-operative day are presented in Table 2.

The lowest D-dimer levels throughout the entire postoperative period were observed in all subjects on the 2nd-3rd post-operative day. A statistically significant difference between the mean D-dimer level on the 2nd-3rd post-operative day, compared to its value on the 1st postoperative day was shown in all patient groups (cementless THR, $p<0.001$; TKR, $p=0.002$; cemented THR, $p=0.005$ ). Furthermore, a statistically significant difference between the D-dimer level on the 2nd-3rd post-operative day and mean baseline value was shown in two patient groups (cementless THR, $p<0.019$; TKR, $p=0.004$ ).

Table 2 Growth differentiation of D-dimer levels in each group of patients

\begin{tabular}{|c|c|c|c|c|c|c|c|c|c|}
\hline \multirow[t]{2}{*}{ The D-dimer levels (ng/m) } & \multicolumn{3}{|c|}{$\begin{array}{l}\text { Cementless total hip replacement } \\
\text { mean age } 58.7 \text { years }\end{array}$} & \multicolumn{3}{|c|}{$\begin{array}{l}\text { Total knee replacement } \\
\text { mean age } 66.9 \text { years }\end{array}$} & \multicolumn{3}{|c|}{$\begin{array}{l}\text { Cemented total hip replacement } \\
\text { mean age } 72.7 \text { years }\end{array}$} \\
\hline & Min & Max & Mean value & Min & Max & Mean value & Min & Max & Mean value \\
\hline 1. The pre-operative D-dimer levels (ng/mL) & 146.43 & $2,676.33$ & $1,077.223$ & 251.66 & $2,960.38$ & $1,025.141$ & 337.28 & $5,315.56$ & $2,075.353$ \\
\hline $\begin{array}{l}\text { 2. D-dimer levels measured } 12 \mathrm{~h} \\
\text { post-operatively }(\mathrm{ng} / \mathrm{mL})\end{array}$ & 1,332.1 & $10,000.00$ & $6,995.55$ & $3,626.18$ & $10,000.00$ & $8,571.276$ & $1,681.13$ & $10,000.00$ & $6,569.658$ \\
\hline $\begin{array}{l}\text { 3. D-dimer levels measured post-operatively } \\
\text { on day } 1 \mathrm{st}(\mathrm{ng} / \mathrm{mL})\end{array}$ & 887.97 & $10,000.00$ & $3,152.338$ & $1,497.00$ & $10,000.00$ & $6,232.967$ & 917.85 & $7,882.89$ & $3,478.125$ \\
\hline $\begin{array}{l}\text { 4. The lowest D-dimer levels measured } \\
\text { post-operatively on days } 2 \text { and } 3(\mathrm{ng} / \mathrm{mL})\end{array}$ & 654.16 & $4,523.55$ & $1,546.635$ & 912.05 & $4,404.59$ & $2,494.083$ & 800.27 & $3,235.43$ & $1,582.428$ \\
\hline $\begin{array}{l}\text { 5. D-dimer levels measured post-operatively } \\
\text { on days } 3 \text { and } 4(\mathrm{ng} / \mathrm{mL})\end{array}$ & $1,312.47$ & $4,523.55$ & $2,536.357$ & $1,441.38$ & $4,404.59$ & $3,331.502$ & $1,050.91$ & $3,921.62$ & $2,174.206$ \\
\hline $\begin{array}{l}\text { 6. The highest D-dimer levels measured } \\
\text { post-operatively on days } 4-10(\mathrm{ng} / \mathrm{mL})\end{array}$ & $1,723.36$ & $7,862.14$ & $3,879.205$ & $2,360.15$ & $8,110.22$ & $5,032.932$ & $2,422.00$ & $10,000.00$ & $4,422.438$ \\
\hline $\begin{array}{l}\text { 7. D-dimer level measured post-operatively } \\
\text { on day } 10(\mathrm{ng} / \mathrm{mL})\end{array}$ & 898.39 & $9,601.73$ & $3,268.066$ & $1,752.18$ & $5,839.16$ & $3,721.137$ & $2,005.96$ & $8,019.52$ & $4,029.627$ \\
\hline
\end{tabular}




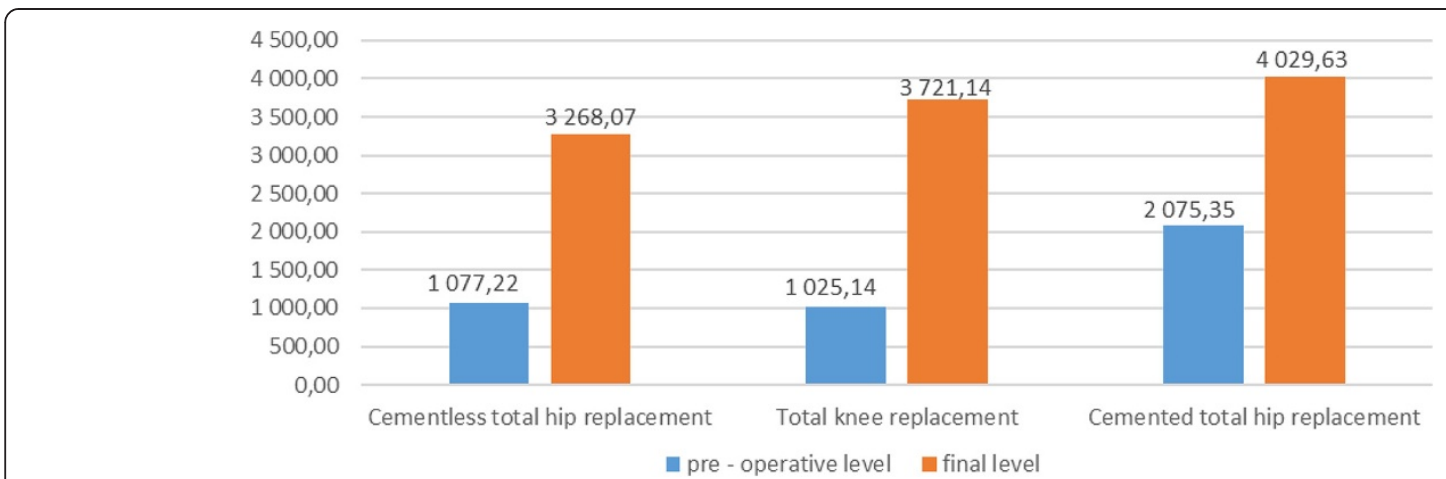

Figure 1 Mean pre-operative and final (10th post-operative day) D-dimer level ( $\mathrm{ng} / \mathrm{ml}$ ) all study groups.

The $p$ value for the cemented THR group was 0.308 ; therefore, it was not considered statistically significant.

The D-dimer levels on the 3rd-4th post-operative day are presented in Table 2.

The subsequent rise of D-dimer level from the 3rd4th post-operative day onwards was observed in all subjects. A statistically significant difference between the mean D-dimer level on the 3rd-4th post-operative day, compared to its value on the 2 nd-3rd post-operative day was shown in all patient groups (cementless THR, $p<0.001$; TKR, $p=0.005$; cemented THR, $p=0.002$ ). The highest $\mathrm{D}$-dimer levels measured post-operatively on days 4th-10th are presented in Table 2.

A statistically significant difference between the mean D-dimer levels on the 4-10th post-operative day, compared to the mean baseline values was observed in all groups (cementless THR, $p<0.001$; TKR, $p=0.002$; cemented THR, $p=0.002$ ). The D-dimer levels on the 10th post-operative day are presented in Table 2.

Figure 1 shows the comparison of pre-operative and final D-dimer levels. The D-dimer level on the 10th post-operative day was still almost doubled compared to the pre-operative value in most patients (Figure 1).

The D-dimer level measured post-operatively on day 10th was still almost twice as high as its pre-operative value in most patients. That is why the physicians, who continue the post-operative management of patients after THR or total knee replacement procedures, may expect the D-dimer concentrations to be significantly elevated. A statistically significant difference between the mean final D-dimer levels compared to the mean baseline (pre-operative) values was observed in all groups (cementless THR, $p<0.001$; TKR, $p=0.002$; cemented THR, $p=0.002$ ). Figures 2,3 and 4 show the mean D-dimer levels for the three study groups, measured throughout the entire follow up period (the vertical bars show the mean value \pm standard deviation) (Figures 2, 3 and 4).

\section{Discussion}

Developing effective measures of venous thromboembolism detection is particularly important in patients undergoing total hip or total knee replacement, as they are at

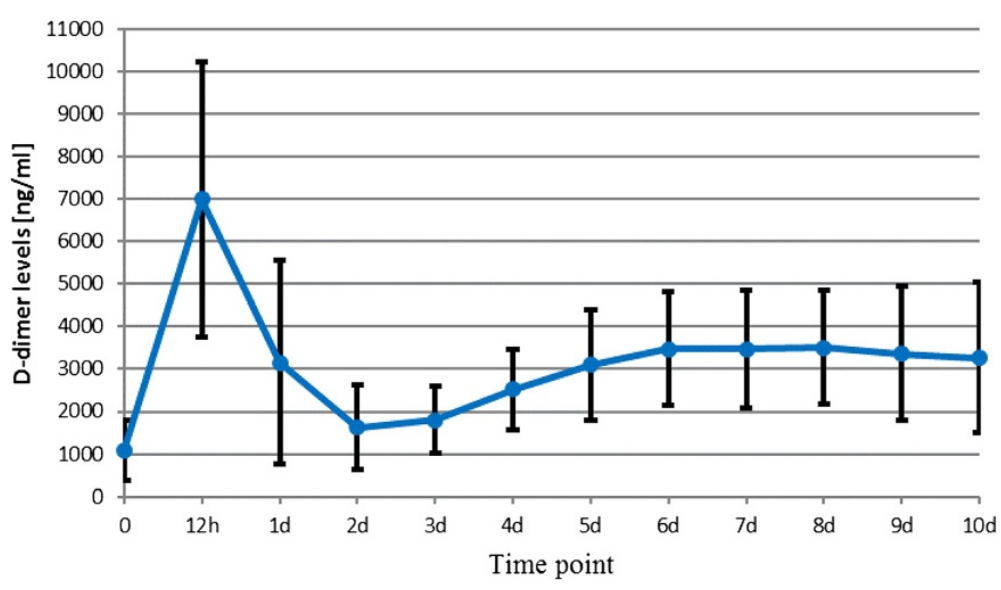

Figure 2 Cementless total hip replacement. 


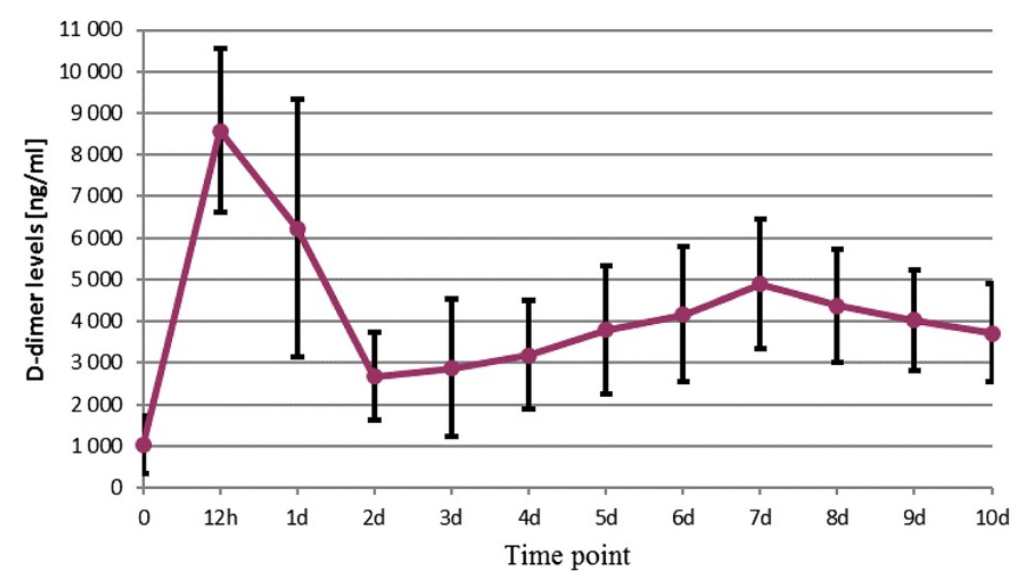

Figure 3 Total knee replacement.

risk of contracting thrombo-embolic complications. In our research, we attempted to determine the applicability of D-dimer level measurements for the detection of venous thromboembolism in these patients. We have determined the ranges of D-dimer values measured during the post-operative period in patients after total hip or total knee replacement. These can be measured using different laboratory methods. Only these methods, characterized by the sensitivity and NPV close to $100 \%$, considered along with the moderate or low clinical probability of VTE according to Wells prediction rule, make it possible to exclude the disease and justify the decision to refrain from treatment with anti-coagulants [8].

As the standard reference values have not been determined yet, the obtained D-dimer level results should be supplemented by the reference range for a specific type of assay. Due to the fact the reference values may be affected by multiple factors, such as patient age, comorbidities, study population or assay type, the obtained results expressed as numbers will be interpreted differently and have variable applications in different clinical settings. Moreover, D-dimer level can take a false negative value in some circumstances, e.g. at the presence of a small thrombus (in isolated distal DVT), in case of temporal delay between the onset of symptoms and the laboratory tests, or the use of anticoagulants (heparin or oral anticoagulants) $[3,6,14]$. The negative D-dimer values in patients with long-lasting symptoms of VTE should always be assessed with caution, as the D-dimer level may drop within 1-2 weeks following the symptom onset to only $1 / 4$ of baseline value. However, the risk of the patient does not decrease if the disease is left untreated. Similarly, the D-dimer level decreases in response to treatment with anticoagulants; it may drop by $25 \%$ of baseline value within $24 \mathrm{~h}$ following the first administration of unfractionated heparin [15].

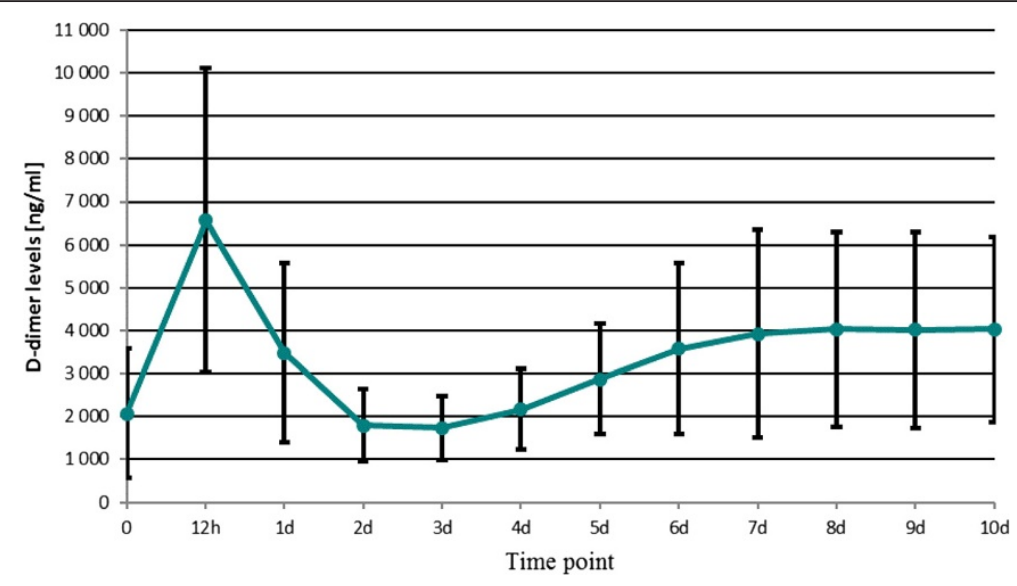

Figure 4 Cemented total hip replacement. 
It should be emphasized that the distribution of D-dimer values throughout the entire post-operative period in our study followed the sinusoid pattern in all patients, with two peaks, and was not specific in any group.

Finally, it should be noted that the elevated D-dimer level is not enough to diagnose VTE in patients after the THR or TKR. Owing to the fact that there are no published papers discussing the issues addressed in our study, it is difficult to relate our findings to the results and observations of other authors.

\section{Conclusions}

1. The D-dimer level almost doubles during the postoperative period in patients after THR or TKR.

2. Higher level of d-dimers in post-operative period in the research group of patients does not relate to higher risk of thromboembolic disease.

\section{Abbreviations}

VTE: venous thromboembolism; DVT: deep vein thrombosis; DIC: disseminated intravascular coagulation; PE: pulmonary embolism; SAB: subarachnoid block; MI: myocardial infarction; RA: rheumatoid arthritis; THR: total hip replacement; TKR: total knee replacement; ASA: American Society of Anesthesiology; FbDP: fibrin degradation products; ELFA: enzyme-linked fluorescent assay; NPV: Negative predictive value; p.o.: orally; i.m.: intramuscularly; i.V:: intravenous; i.e: that is; approx.: approximately; HES: hydroxyethyl starch; BMI: body mass index; P: level of significance; 1st: first; 2nd: second; 3rd: third; 4th: fourth; 10 th: tenth.
\end{abstract}

\section{Competing interests}

The authors declare that they have no competing interests.

\section{Authors' contributions}

$L R$, WM and PB conceived of the study, participated in its design and coordination and helped to draft the manuscript. PB carried out the design of the study and the statistical analysis, and he was the principal coordinator of all aspects of this research. WW and KK carried out the editing of the text and graphics and prepared the edition of this manuscript for publication. KK was responsible for the translation into English and editing the text. All authors read and approved the final manuscript.

\section{Authors' information}

Piotr Bytniewski is the first author.

\section{Acknowledgements}

All procedures were performed at the Department of Orthopedics and Traumatology, Health Maintenance Organization in Turek, Poduchowne 1 street, 62-700 Turek, Poland.

\section{Author details}

'Department of Anaesthesiology, Health Maintenance Organization in Turek, Turek, Poland. ${ }^{2}$ Faculty of Physical Education and Health Preservation, The State School of Professional Higher Education in Konin, Konin, Poland. ${ }^{3}$ Department of Anaesthesiology and Intensive Care, Medical University of Łódź, Łódź, Poland. ${ }^{4}$ Department of Traumatology, Orthopaedics and Hand Surgery, Medical University of Poznań, Poznań, Poland. ${ }^{5}$ Department of Orthopaedics and Traumatology, Health Maintenance Organization in Turek, Turek, Poland. ${ }^{6}$ Health Maintenance Organization in Turek, Turek, Poland.

Received: 19 May 2014 Accepted: 22 September 2014

Published online: 10 October 2014

\section{References}

1. Dembińska-Kieć A, Naskalski JW: Diagnostyka laboratoryjna z elementami biochemii klinicznej. Urban \& Partner: Wrocław; 2009.
2. Bick RL, Baker WF: Diagnostic efficacy of the D-dimer assay in disseminated intravascular coagulation (DIC). Thromb Res 1992, 65:785-790.

3. Nalewajka M, Gaździk TSZ: Przydatność badania stężenia D-dimerów w surowicy krwi w diagnostyce zakrzepicy żylnej u chorych po alloplastyce stawów biodrowych i kolanowych. J Orthop Trauma Surg Rel Res 2008, 10:25-34.

4. Cordell-Smith JA, Williams SC, Harper WM, Gregg PJ: Lower limb arthroplasty complicated by deep venous thrombosis. Prevalence and subjective outcome. J Bone Joint Surg (Br) 2004, 86:99-102.

5. Kusz D, Wojciechowski P, Totuszynski J, Wróbel W: Powikłania totalnych alloplastyk stawów biodrowych. Kwart Ortop 2002, 2:93-97.

6. Tomkowski WZ, Kuca P: Żylna choroba zakrzepowo - zatorowa w gabinecie lekarza rodzinnego. Gdańsk: Via Medica; 2010

7. Eichinger S, Weltermann A, Philipp K, Hafner E, Kaider A, Kittl EM, Brenner B, Mannhalter C, Lechner K, Kyrle PA: Prospective evaluation of hemostatic system activation and thrombin potential in healthy pregnant women with and without factor V Leiden. J Thromb Haemost 1999, 82:1232-1236.

8. Torbicki A, Perrier A, Konstantinides S, Agnelli G, Galie N, Pruszczyk P, Bengel F, Brady AJB, Ferreira D, Janssens U, Klepetko W, Mayer E, Remy-Jardin M, Bassand JP: Guidelines on the diagnosis and management of acute pulmonary embolism: the task force for the diagnosis and management of acute pulmonary embolism of the European Society of Cardiology (ESC). Eur Heart J 2008, 29:2276-2315.

9. ACEP Clinical Policies Committee. Clinical Policy: Critical issues in the evaluation and management of adult patients presenting with suspected lower-extremity deep venous thrombosis. Ann Emerg Med 2003, 42:124-135.

10. Fesmire FM, Brown MD, Espinosa JA, Shih RD, Silvers SM, Wolf SJ, Decker WW American College of Emergency Physicians: Critical issues in the evaluation and management of adult patients presenting to the emergency department with suspected pulmonary embolism. Ann Emerg Med 2011, 57(6):628-652.

11. De Moerloose P: Performances of the Vidas D-dimer new assay for the exclusion of venous thromboembolism. J Thromb Haemost 2001, 85:185-186.

12. Fijałkowska A: D-dimery w żylnej chorobie zakrzepowo-zatorowej. Aktualności bioMérieux, Warszawa 2010, 54:3-7.

13. Chmielewski D, Górecki A, Kusz D, Małdyk P, Marczyński W, Tomkowski W: Zasady profilaktyki żylnej choroby zakrzepowo-zatorowej w ortopedii i traumatologii narządu ruchu. Ortopedia Traumatologia Rehabilitacja. Medsportpress 2009, 1(6):86-92. Vol. 11.

14. Jennersjo CM, Fagerberg IH, Karlander SG, Lindahl TL: Normal D-dimer concentration is a common finding in symptomatic outpatients with distal deep vein thrombosis. Blood Coagul Fibrinolysis 2005, 16:517-523.

15. Couturaud F, Kearon C, Bates SM, Ginsberg JS: Decrease in sensitivity of D-dimer for acute venous thromboembolism after starting anticoagulant therapy. Blood Coagul Fibrinolysis 2002, 13:241-246.

\section{doi:10.1186/s13018-014-0089-0}

Cite this article as: Bytniewski et al:: The dynamics of D-dimer level fluctuation in patients after the cemented and cementless total hip and total knee replacement. Journal of Orthopaedic Surgery and Research 2014 9:89.

\section{Submit your next manuscript to BioMed Central and take full advantage of:}

- Convenient online submission

- Thorough peer review

- No space constraints or color figure charges

- Immediate publication on acceptance

- Inclusion in PubMed, CAS, Scopus and Google Scholar

- Research which is freely available for redistribution 